\title{
PENGARUH STRUKTUR KEPEMILIKAN DAN STRUKTUR MODAL TERHADAP HARGA SAHAM
}

\author{
Rani Raharjanti \\ Nur Setyowati \\ Jurusan Akuntansi Politeknik Negeri Semarang
}

\begin{abstract}
This paper aims to investigate the short and long run behavior of ownership structure, capital structure and Indonesian Stock Price over the period from 2007 to 2016. To capture the long run relationships, we used the panel cointegration by Pedroni (1999, 2000, 2004), while the short run relationship are measured by Vector Error Correction Model (VECM). The main findings are as follows. First, the result of most results of Pedroni's panel cointegration tests, suggest the null hypothesis of no cointegration is rejected. In consequence, this result suggests that there is a cointegration between stock price, managerial ownership, institutional ownership, public ownership, debt to equity ratio and earnings per share. Second, the results of VECM indicate that in the short run, only managerial ownership that will influence the stock price.
\end{abstract}

Keywords: Stock price, ownership, capital structure, corporate governance.

\section{PENDAHULUAN}

Harga saham dapat dipengaruhi oleh berbagai macam faktor yang didominasi oleh kinerja perusahaan yang menerbitkan saham dan perspektif yang lebih luas dimana kekuatan pasar sangat signifikan (Menon, 2016). Harga saham dapat berubah setiap hari sebagai hasil dari kekuatan pasar tersebut. Evans (2009) mengemukakan bahwa harga saham berfungsi sebagai sinyal untuk alokasi yang tepat dari modal antar perusahaan, investor menggunakan harga saham untuk membuat keputusan investasi.
Di negara berkembang, mekanisme tata kelola perusahaan seperti kepemilikan institusional, kepemilikan publik, kepemilikan manajerial, auditor eksternal dan lembaga pemeringkat terbukti kurang berkembang. Sun dkk (2016) menambahkan bahwa struktur kepemilikan merupakan instrumen penting dalam mengurangi masalah keagenan. Penelitian terdahulu (Quang dan Xin, 2013; Pirzada dkk, 2015; Sun dkk, 2016) mengkonfirmasi bahwa konflik keagenan dalam struktur kepemilikan memiliki dampak pada kinerja perusahaan. 
Pilihan pendanaan mengacu pada keputusan utama perusahaan karena struktur modal optimal merepresentasikan campuran pembiayaan perusahaan dapat memaksimalkan harga saham dan nilai perusahaan (Vatavu, 2015). Menon (2016) menemukan bahwa terdapat hubungan positif antara jumlah modal, harga saham dan debt equity ratio.

Penelitian ini menguji pengaruh struktur kepemilikan dan struktur modal terhadap harga saham di Indonesia. Dengan melakukan penelitian ini diharapkan terdapat pengaruh struktur kepemilikan dan struktur modal terhadap harga saham. Penelitian ini mengadopsi dari penelitian yang dilakukan oleh Sun dkk (2016) namun terdapat perbedaan. Pertama, variabel kepemilikan pada penelitian ini memasukkan kepemilikan publik. Kedua, variabel struktur modal diproksikan oleh debt to equity ratio dan earning per share, kemudian struktur modal menjadi variabel independen. Ketiga, variabel dependen diwakili oleh harga saham. Keempat, dalam penelitian ini menggunakan panel cointegration model dan vector error correction model (VECM). Berdasarkan argumen-argumen teoritis dan penemuan empiris terkini diharapkan terdapat hubungan struktur kepemilikan dan struktur modal dengan harga saham di Indonesia.

\section{TELAAH TEORITIS DAN}

\section{PENGEMBANGAN HIPOTESIS}

\section{Kepemilikan Managerial}

Teori agensi menyarankan bahwa meningkatnya proporsi kepemilikan saham oleh manajer menyebabkan semakin selarasnya kepentingan antara manajer dan pemegang saham (Jensen dan Meckling, 1976). Hal ini juga berarti bahwa perusahaanperusahaan yang manajernya memiliki banyak modal saham hanya memerlukan sedikit pemantauan oleh dewan komisaris dimana memiliki implikasi untuk fungsifungsi dan struktur (Munisi dkk, 2014). Sebagai tambahan, Munisi dkk (2014) menemukan bahwa kepemilikan manajerial dan ukuran dewan berasosiasi secara negatif. Penelitian yang dilakukan oleh Sepasi dkk (2016) menunjukkan bahwa kepemilikan manajerial memiliki pengaruh negatif dan signifikan terhadap kualitas pengungkapan.

Berdasarkan hubungan antara kepemilikan manajerial dan harga saham, maka dapat dirumuskan hipotesis sebagai berikut:

H1. Terdapat pengaruh kepemilikan managerial terhadap harga saham.

\section{Kepemilikan Institutional}

Al-Najjar dan Taylor (2008) menyatakan bahwa kepemilikan institusional memainkan 
peran kunci dalam melakukan monitoring perusahaan dimana para investor menanamkan modalnya. Pemilik perusahaan memiliki hak yang berbeda, seperti hak pemilihan dewan direksi. Leverage perusahaan menurun ketika kepemilikan institusional meningkat (Chung dan Wang, 2014). Chung dan Wang (2014) menambahkan bahwa bukti monitoring terhadap leverage perusahaan dan leverage suboptimal menjadi lebih jelas ketika investor institusional cenderung kurang memiliki hubungan bisnis dengan sebuah perusahaan atau informasi asimetris yang tinggi di pasar. Namun, Alzeaideen dan Al-Rawash (2014) mengkonfirmasi sebuah bukti bahwa kepemilikan institusional tidak memiliki pengaruh terhadap harga saham.

Berdasarkan kombinasi argumenargumen diatas, maka dapat dirumuskan hipotesis sebagai berikut:

H2. Terdapat pengaruh kepemilikan institutional terhadap harga saham

\section{Kepemilikan Publik}

Kepemilikan publik juga dapat berpengaruh terhadap harga saham. Perusahaan modern menghadapi isu-isu terkait dengan pemisahaan kepemilikan dan pengendalian. Kepemilikan publik menginginkan pihak manajemen untuk memonitor guna memastikan kepentingan pemegang saham. Sementara pemegang saham terbanyak dan block shareholders memiliki sumberdaya dan insentif untuk mengawasi kinerja manajemen, struktur pemegang saham yang tersebar menderita karena masalah "free rider" (Yu, 2013). Yu (2013) menambahkan bahwa kepemilikan publik memiliki hubungan bentuk $U$ dengan kinerja perusahaan. Sementara itu, Hou, dkk (2012) dan Al-Qallaf (2015) berargumentasi bahwa kepemilikan publik memiliki hubungan positif terhadap harga saham. Dikarenakan alasan-alasan tersebut, maka dirumuskan hipotesis sebagai berikut:

H3. Terdapat pengaruh kepemilikan publik terhadap harga saham.

\section{Struktur Modal}

Semenjak Modigliani dan Miller mengemukakan teori MM di tahun 1958 yang menyatakan bahwa struktur modal tidak relevan dalam proses determinasi nilai perusahaan di suatu pasar sempurna, isu struktur modal digeneralisir diantara kepentingan ekonomis keuangan (Li, Munir dan Karim, 2017). Berdasarkan teori keuangan modern, struktur modal mengacu pada cara suatu perusahaan dalam hal ini pendanaannya guna melaksanakan operasional perusahaan melalui kombinasi kepemilikan modal, utang dan pertukaran kredit (Quang dan Xin, 2013). 
Seperti yang dikemukakan oleh Menon (2016), terdapat hubungan positif antara jumlah ekuitas, harga saham dan debt equity ratio. Menon (2016) menambahkan bahwa terdapat indikasi persepsi negatif oleh investor terhadap kenaikan utang dan berakibat pasar menurun. Hasil penelitian dari Vatavu (2015) mengindikasikan bahwa kinerja perusahaan di Romania meningkat ketika perusahaan menghindari utang dan beroperasi berdasarkan ekuitasnya.

Berdasarkan argumen-argumen di atas, maka dapat dirumuskan hipotesis sebagai berikut:

H4. Terdapat pengaruh struktur modal terhadap harga saham.

\section{METODE PENELITIAN}

\section{Deskripsi Variabel}

Pada penelitian ini, harga saham merupakan variabel dependen dimana didefinisikan oleh harga penutupan saham pada tahun yang bersangkutan. Kepemilikan manajerial dihitung dari rasio kepemilikan saham yang dimiliki oleh dewan komisaris dan direksi serta dipublikasikan di laporan tahunan (Quang dan Xin, 2013; Munisi dkk, 2014; Sun dkk, 2016). Kepemilikan institutional diukur dengan proporsi saham yang dimiliki oleh institusi (Chung dan Wang, 2014; Pirzada dkk, 2015; Sun dkk, 2016).
Kepemilikan publik diformulasikan dengan rasio saham yang dimiliki oleh publik. Struktur modal diukur dengan debt to equity ratio dan earning per share ( $\mathrm{Yu}, 2013$; Pirzada dkk, 2015; Huang dan Ni, 2016; Menon, 2016).

\section{Data}

Data dalam penelitian ini didapatkan dari website resmi Bursa Efek Indonesia (www.idx.co.id), dimana data diambil dari laporan tahunan dari tahun 2007 sampai dengan tahun 2016. Jumlah total perusahaan yang digunakan adalah 40 perusahaan.

\section{Metode Analisis Data}

Pengujian hipotesis pada penelitian ini menggunakan model VECM dengan menggunakan perangkat lunak Eviews. Analisis data dilaksanakan melalui beberapa tahap, yakni Panel unit root test, panel cointegration test, analisis kausalitas Granger, analisis impulse response function, dan analisis variance decomposition.

\section{Pembahasan Hasil}

Dalam penelitian ini digunakan model panel cointegration dan vector error correction model (VECM) untuk mengeksplorasi pengembangan hipotesis. Panel cointegration model digunakan untuk menguji bagaimana struktur kepemilikan dan 
struktur modal memiliki hubungan jangka panjang dengan harga saham. VECM digunakan untuk menguji bagaimana hubungan jangka pendek antara struktur kepemilikan dan struktur modal dengan harga saham.

\section{Panel Unit Root Test}

Uji panel unit root digunakan untuk menguji asumsi rangkaian data yang seimbang pada perbedaan pertama. Uji ini dilakukan sebelum menguji tes kointegrasi. Terlepas dari Levine, Lin dan Chu (2002), juga dilakukan uji panel unit root berdasarkan Im, Pesaran, dan Shin (2003), serta Fisher type test (1979). Tabel 1 menggambarkan hasil dari panel unit root test. Hasil dari semua panel unit root tests mendukung semua variabel pada tingkat signifikansi 5\%.

\section{Panel Cointegration Test}

Hasil dari Panel Cointegration Test ditunjukkan di tabel 2, tes statistik empat pertama adalah "within" dimension (panel statistics) cointegration dan sisanya adalah "between" dimension (group statistics) cointegration. Kointegrasi akan ada jika hipotesis nol dari tidak adanya kointegrasi ditolak. Hasil dari tabel 2 menunjukkan bahwa Panel V-Stat signifikansi pada $10 \%$, Panel PP-Stat dan Panel ADF-Stat signifikansi pada $1 \%$, sementara Panel rho-Stat tidak dapat menolak hipotesis nol. Dalam uji statistik kelompok, Group PP-Stat dan Group ADFStat menunjukkan kointegrasi pada level signifikansi $1 \%$, tetapi tidak terdapat kointegrasi dalam Group rho-Stat. Jadi, sebagian besar hasil tes kointegrasi panel Pedroni yang menyarankan hipotesis nol dari tidak adanya kointegrasi ditolak. Konsekuensinya, hasil tersebut menyarankan bahwa terdapat kointegrasi jangka panjang antara harga saham, kepemilikan manajerial, kepemilikan institutional, kepemilikan publik, DER dan EPS.

\section{Analisis Kausalitas Granger}

Uji kausalitas dilakukan untuk mengetahui apakah suatu variabel endogen dapat diperlakukan sebagai variabel eksogen. Hasil pada tabel 3 menunjukkan bahwa bidirectional causality, dapat ditemukan hubungan antara harga saham dan kepemilikan manajerial. One-way causality dapat ditemukan hubungan dari EPS dengan harga saham dimana harga saham secara signifikan dipengaruhi oleh EPS. Selanjutnya one way causality dapat dilihat pada konteks kepemilikan manajerial dan institusional serta kepemilikan institusional dengan EPS. Hal ini mengindikasikan bahwa kepemilikan manajerial dan EPS mempengaruhi kepemilikan institusional. 
Tabel 1: Panel unit root test

\begin{tabular}{|c|c|c|c|c|c|c|c|c|}
\hline & \multicolumn{2}{|c|}{ Levin, Lin, and Chu } & \multicolumn{2}{|c|}{$\begin{array}{c}\text { Im, Pesaran, and Shin W- } \\
\text { stat }\end{array}$} & \multicolumn{2}{|c|}{ ADF-Fisher } & \multicolumn{2}{|c|}{ PP-Fisher } \\
\hline Model & $\begin{array}{l}\text { Without } \\
\text { Trend }\end{array}$ & With Trend & $\begin{array}{l}\text { Without } \\
\text { Trend }\end{array}$ & With Trend & $\begin{array}{l}\text { Without } \\
\text { Trend }\end{array}$ & With Trend & $\begin{array}{l}\text { Without } \\
\text { Trend }\end{array}$ & With Trend \\
\hline \multicolumn{9}{|c|}{ Levels } \\
\hline PRICE & $-6.29074^{* * *}$ & $-15.459 * * *$ & -0.6133 & -1.63262 & 97.6704 & 120.678 & 78.7224 & 108.335 \\
\hline MAN & -46.8548 & -67.5399 & -12.2339 & -9.03106 & 132.432 & 143.189 & 170.805 & 183.573 \\
\hline INS & 12.6818 & 15.7544 & 1.55109 & 2.07394 & 69.6402 & 49.1654 & 168.454 & $' 156.310^{* * *}$ \\
\hline PUB & -1.93666 & -1.04862 & 1.00982 & 1.74117 & 112.754 & 77.4134 & 159.184 & 119.747 \\
\hline DER & $-6.1366 * * *$ & $-6.4197 * * *$ & -1.84662 & -0.34076 & 109.407 & 91.6741 & 158.904 & 189.708 \\
\hline EPS & -0.21655 & -0.17138 & 0.73611 & -0.61377 & 51.3754 & 84.876 & 120.166 & 151.053 \\
\hline \multicolumn{9}{|c|}{ First Difference } \\
\hline PRICE & $-6.59882^{* * * *}$ & $-8.12109^{* * * *}$ & $2.78329^{* * *}$ & -0.34417 & $122.414^{* * * *}$ & $99.2397^{*}$ & $276.044^{* * *}$ & $283.775 * * *$ \\
\hline MAN & $12.6693^{* * *}$ & $11.4914 * * *$ & $-1.02328 * * *$ & $-0.18515 * * *$ & $81.1436 *$ & $85.4043^{*}$ & $293.076 * * *$ & $316.355 * * *$ \\
\hline INS & 13.6152 & 8.71342 & $-1.89616^{* *}$ & $-0.88306^{* *}$ & $107.662 * * *$ & $112.171 * * *$ & $299.536 * * *$ & $315.948 * * *$ \\
\hline PUB & $-3.9486 * * *$ & $-12.015 * * *$ & $-1.63474 * *$ & -0.59505 & $126.637 * * *$ & $116.519 * * *$ & $248.358 * * *$ & $266.510 * * *$ \\
\hline DER & 0.53023 & 2.23675 & $-3.52536^{* * *}$ & $-0.43338 *$ & $136.498 * * *$ & $101.011^{* * *}$ & $317.682 * * *$ & $265.374 * * *$ \\
\hline EPS & $-19.036 * * *$ & $-23.505 * * *$ & $-6.3370 * * *$ & $-2.07708 * *$ & $154.957 * * *$ & $112.502 * * *$ & $279.008 * * *$ & $257.477 * * *$ \\
\hline
\end{tabular}

Note: The signs $* * *, * *$ and $*$ denote significance at $1 \%, 5 \%$ and $10 \%$, respectively.

Tabel 2: Panel cointegration tests result

\begin{tabular}{lrr}
\hline & Without Trend & With Trend \\
\hline Panel v-Stat & -3.385214 & -3.785134 \\
Panel rho-Stat & $0.9996^{*}$ & $0.9999^{*}$ \\
& 5.16126 & 5.916069 \\
Panel PP-Stat & 1.0000 & 1.0000 \\
& -7.043789 & -14.48486 \\
Panel ADF-Stat & $0.0000^{* * *}$ & $0.0000^{* * *}$ \\
& -4.319437 & -6.192835 \\
Group rho-Stat & $0.0000^{* * *}$ & $0.0000^{* 4 *}$ \\
& 7.556929 & 8.05069 \\
Group PP-Stat & 1.0000 & 1.0000 \\
& -13.22047 & -21.32921 \\
Group ADF-Stat & $0.0000^{* * *}$ & $0.0000^{* * *}$ \\
& -5.148248 & -5.207758 \\
& $0.0000^{* * *}$ & $0.0000^{* * *}$
\end{tabular}

Note: The signs ${ }^{* * *},{ }^{* *}$ and ${ }^{*}$ denote significance at $1 \%, 5 \%$ and $10 \%$, resp $\measuredangle$ tively.

\section{Hasil dari Vector Error Correction Model}

Vector error correction model (VECM) digunakan pada penelitian ini karena terdeteksi adanya kointegrasi diantara rangkaian data dan terdapat hubungan jangka panjang diantara variabel (lihat tabel 2). Selain itu, semua rangkaian data bersifat stasioner pada first difference (lihat tabel 1) dimana data tersebut tidak dapat memenuhi persyaratan asumsi VAR. Oleh karena itu, diterapkan VECM untuk mengevaluasi karakteristik jangka pendek, perubahan harga saham dipengaruhi oleh variabelnya sendiri pada tingkat signifikansi $1 \%$, kepemilikan manajerial pada tingkat signifikansi $10 \%$, dan 
EPS pada tingkat signifikansi $5 \%$ di lag pertamanya. Dalam jangka panjang, variabel kepemilikan manajerial, DER, dan EPS memiliki pengaruh terhadap harga saham pada tingkat signifikansi $1 \%$, sementara kepemilikan institusional dan kepemilikan publik mempengaruhi harga saham pada tingkat signifikansi $10 \%$.

\section{Impulse Response Function (IRF)}

Selanjutnya, analisis IRF dijalankan untuk menentukan respon suatu variabel endogen terhadap guncangan variabel tertentu. Gambar 1 menunjukkan bagaimana harga saham merespon dari waktu ke waktu guncangan inovasi dalam kepemilikan manajerial, kepemilikan institusional, kepemilikan publik, DER dan EPS.

Tabel 3: Panel granger causality test result

\begin{tabular}{lccc} 
Null Hypothesis: & Obs & F-Statistic & Prob. \\
\hline \hline DMAN does not Granger Cause & & & \\
DPRICE & $\mathbf{3 1 6}$ & $\mathbf{1 0 . 8 4 8 2}$ & $\mathbf{3 . E}-05$ \\
DPRICE does not Granger Cause DMAN & $\mathbf{3 . 9 3 9 9 9}$ & $\mathbf{0 . 0 2 0 4}$ \\
\hline \hline DEPS does not Granger Cause & & & \\
DPRICE & \multirow{3}{*}{$\mathbf{4 1 9}$} & $\mathbf{4 . 4 7 4 5 4}$ & $\mathbf{0 . 0 1 2 1}$ \\
DPRICE does not Granger Cause DEPS & & 0.37384 & 0.6884 \\
\hline \hline DINS does not Granger Cause DMAN & \multirow{3}{*}{316} & $\mathbf{3 . 9 1 5 4 5}$ & $\mathbf{0 . 0 2 0 9}$ \\
DMAN does not Granger Cause DINS & & 0.29414 & 0.7454 \\
\hline \hline DEPS does not Granger Cause DINS & \multirow{3}{*}{319} & $\mathbf{6 . 5 7 3 0 8}$ & $\mathbf{0 . 0 0 1 6}$ \\
DINS does not Granger Cause DEPS & & 0.09752 & 0.9071 \\
\hline \hline
\end{tabular}

Hasil penelitian menunjukkan bahwa terdapat guncangan positif dan kenaikan efek pada kepemilikan manajerial sehingga meningkatkan harga saham dari tahun pertama hingga sepuluh tahun kedepan. Tren yang sama terlihat pada kepemilikan publik dan DER terhadap harga saham, kedua variabel tersebut memiliki pengaruh positif tetapi pengaruhnya cukup stabil dalam kurun waktu tertentu. Temuan menarik ditemukan pada kepemilikan institusional dan EPS karena guncangan kepemilikan institusional hampir tidak berdampak pada harga saham dan EPS memiliki konsekuensi negatif terhadap harga saham. 
Gambar 1. Generalized impulse response functions of stock price
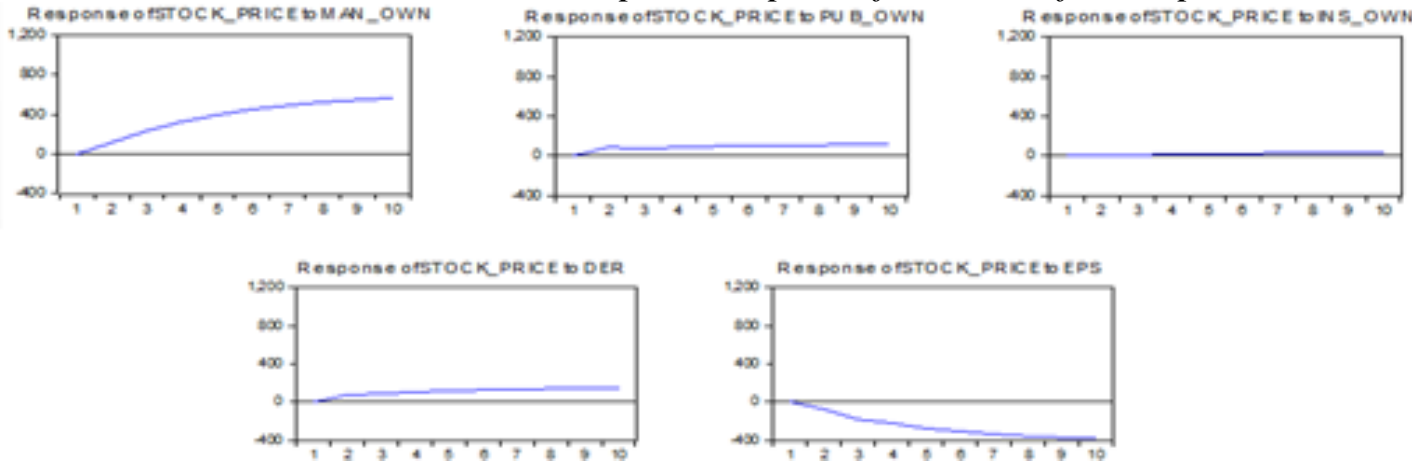

Tabel 4: Hasil dari Vector Error Correction Model (VECM)

\begin{tabular}{|c|c|c|c|}
\hline Veriable & Cosfficinat & T-Smanisdic & Explanafion \\
\hline \multicolumn{4}{|c|}{ Short-Torm } \\
\hline $\begin{array}{l}\text { D(DPRICE(- } \\
\text { 1)) } \\
\text { D(DPRICE - }\end{array}$ & -0.545647 & -9.50549 & $\begin{array}{l}\text { Sigeifiteant at } l 36 \\
\text { Level } \\
\text { Sigetifieant at } 136\end{array}$ \\
\hline 2) & -0.307553 & -5.2168 & Level \\
\hline $\mathrm{D}(\mathrm{DMANN}(-1))$ & -6547.089 & $\underset{-1.75589}{\bullet}$ & \multirow{2}{*}{ 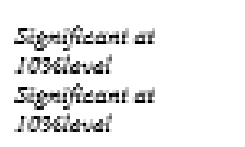 } \\
\hline $\mathrm{D}(\mathrm{DMANN}(-2))$ & 4725.19 & 1.72419 & \\
\hline$D(\operatorname{DNNS}(-1))$ & 1493.841 & 0.96379 & Not Signtifitednt \\
\hline $\mathrm{D}(\mathrm{DNNS}(-2))$ & 429.0605 & 0.28422 & Not Signtifiednt \\
\hline $\mathrm{D}(\mathrm{DPUB}(-1))$ & 840.8931 & 0.55507 & Not Signtifiednt \\
\hline $\mathrm{D}(\mathrm{DPUB}(-2))$ & 306.2597 & 0.20208 & Not Signifiedant \\
\hline $\mathrm{D}(\mathrm{DDER}(-1))$ & -14.22909 & -0.31584 & Not Signtifiedet: \\
\hline $\mathrm{D}(\mathrm{DDER}(-2))$ & -14.22909 & -0.31584 & Not Signtifiednt \\
\hline $\mathrm{D}(\mathrm{DEPS}(-1))$ & 1.166149 & 2.10292 & Sigreificant at I3kidvil \\
\hline $\mathrm{D}(\mathrm{DEPS}(-2))$ & 0.442523 & 0.86133 & Not Signtifitant \\
\hline $\begin{array}{l}\text { C } \\
\text { CointEgl }\end{array}$ & $\begin{array}{r}-62.40947 \\
0.017703\end{array}$ & & \\
\hline \multicolumn{4}{|c|}{ Lang-Term } \\
\hline $\operatorname{DMLAN}(-1)$ & 416473.3 & 17.9382 & $\begin{array}{l}\text { Sigretifieant at } 1 \% \\
\text { Level } \\
\text { Sigrefifieant at }\end{array}$ \\
\hline $\operatorname{DnNS}(-1)$ & -24620.02 & -1.78623 & 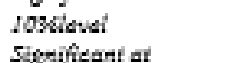 \\
\hline DPUB $(-1)$ & -27739.97 & -1.68626 & $\begin{array}{l}\text { I0\%oldevit } \\
\text { Sigreifieant at } 136\end{array}$ \\
\hline $\operatorname{DDER}(-1)$ & -2999.896 & -3.71882 & Level \\
\hline DEPS(-1) & -31.44314 & -6.52116 & $\begin{array}{l}\text { Sigrifieant at } 2 \% \\
\text { tevel }\end{array}$ \\
\hline $\mathrm{c}$ & 105.9367 & & \\
\hline
\end{tabular}

\section{Analisis Variance Decomposition}

Tabel 5 menunjukkan dekomposisi ragam kesalahan peramalan dari harga saham. Kepemilikan manajerial menempati urutan kedua dengan pengaruh terhadap harga saham sebesar $16,087 \%$ dalam 10 tahun, diikuti oleh EPS, DER, kepemilikan publik, dan kepemilikan institusional sebagai komponen harga saham paling penting dari satu sampai sepuluh tahun kedepan.

Tabel 5: The Forecast Error Variance Decomposition of Stock Price

\begin{tabular}{cccccccc}
\multicolumn{1}{c}{$\begin{array}{c}\text { Variance Decomposition of STOCK_PRICE: } \\
\mathrm{d}\end{array}$} & S.E. & RICE & NTOCK_P MAN_OW PUB_OW & N & INS_OWN & DER & EPS \\
\hline \hline 1 & 860.0389 & 100.0000 & 0.000000 & 0.000000 & 0.000000 & 0.000000 & 0.000000 \\
2 & 1146.829 & 97.65730 & 0.953263 & 0.555932 & 0.003446 & 0.397939 & 0.432124 \\
3 & 1446.200 & 93.71324 & 3.244024 & 0.583963 & 0.002861 & 0.603597 & 1.852319 \\
4 & 1726.471 & 89.70964 & 5.842598 & 0.664792 & 0.011904 & 0.787068 & 2.984002 \\
5 & 2000.062 & 85.91256 & 8.266452 & 0.722058 & 0.017636 & 0.922797 & 4.158501 \\
6 & 2263.036 & 82.67816 & 10.39173 & 0.762046 & 0.024314 & 1.027251 & 5.116490 \\
7 & 2515.823 & 79.92249 & 12.20189 & 0.794203 & 0.030050 & 1.108894 & 5.942472 \\
8 & 2758.102 & 77.62106 & 13.72604 & 0.818224 & 0.035142 & 1.173053 & 6.626481 \\
9 & 2990.085 & 75.69042 & 15.00760 & 0.837420 & 0.039528 & 1.224533 & 7.200502 \\
10 & 3212.188 & 74.06903 & 16.08725 & 0.852639 & 0.043299 & 1.266264 & 7.681518 \\
\hline \hline
\end{tabular}




\section{KESIMPULAN}

Penelitian ini menginvestigasi hubungan antara struktur kepemilikan dan struktur modal dengan harga saham. Terdapat kointegrasi jangka panjang antara harga saham, kepemilikan manajerial, kepemilikan institusional, kepemilikan publik, DER dan EPS. Dalam jangka pendek ditemukan bahwa harga saham dipengaruhi oleh variabel mereka sendiri, kepemilikan manajerial dan EPS.

Hal ini mengimplikasikan bahwa kepemilikan manajerial secara negatif berhubungan dengan harga saham mengindikasikan bahwa pemegang saham manajerial tertinggi dapat membantu meningkatkan kepercayaan investor pada suatu perusahaan seperti kekhawatiran apakah harga saham akan turun.

\section{Keterbatasan dan Saran}

Dalam penelitian ini terdapat beberapa keterbatasan seperti tidak lengkapnya data yang dimiliki oleh Bursa Efek Indonesia sehingga menyebabkan sampel dari penelitian ini terbatas. Penelitian ini hanya menggunakan struktur kepemilikan untuk mewakili corporate governance. Penelitian selanjutnya diharapkan dapat menambah beberapa variabel seperti auditor eksternal dan lembaga pemeringkatan untuk mengungkapkan apakah harga saham juga dipengaruhi oleh mekanisme corporate governance. Selain itu, penting juga untuk mengungkapkan secara empiris dengan menambahkan negara lain di Asia Tenggara sebagai sampel penelitian.

Setelah meneliti tentang hubungan antara harga saham dan EPS, dapat dilihat bahwa terdapat hubungan positif antara EPS dan harga saham. Hasil menunjukkan bahwa secara statistik signifikan pada level $5 \%$. Hal ini mengindikasikan bahwa perusahaan mampu meningkatkan kemakmuran investor maka tingkat kepercayaan investor juga meningkat. Hal ini akan menstimulasi investor untuk menginvestasikan dana mereka di perusahaan.

\section{DAFTAR PUSTAKA}

Al-Najjar, Bashir and Peter Taylor, 2008. "The Relationship Between Capital Structure and Ownership Structure: New Evidence from Jordanian Panel Data". Managerial Finance, 34 (12), 919-933.

Al-Qallaf, Huda, 2015. "The Effect of Ownership Structure on Stock Prices During Crisis Periods: Case Study in Kuwait Stock Market". The 2015 WEI International Academic Conference Proceedings, 130-136.

Alzeaideen, Khaled Abdulwahab and Sara Zakaria Al-Rawash, 2014. "The Effect of Ownership Structure on Share Price Volatility of Listed Companies in Amman Stock Exchange". Research Journal of Finance and Accounting, 5 (6), 192-201. 
Chung, Chune Young and Kainan Wang, 2014. "Do Institutional Investors Monitor Management? Evidence from the Relationship between Institutional Ownership and Capital Structure". North American Journal of Economics and Finance, 30, 203-233.

Evans, Alicia Davis, 2009. "Do Individual Investors Affect Share Price Accuracy? Some Preleminary Evidence". Law \& Economics Working Paper Archive: 2003-2009, Art. 75.

Hou, Wenxuan, Jing Ming Kuo, and Edward Lee, 2012. "The Impact of State Ownership on Share Price Informativeness: The Case of The Split Share Structure Reform in China". British Accounting Review, 44, 248-261.

Huang, Paoyu and Yensen Ni, 2016. "Board Structure and Stock Price Informativeness in Terms of Moving Average Rules". The Quarterly Review of Economics and Finance, 1-9.

Im, Pesaran and Shin, 2003. "Testing for Unit Roots in Heterogeneous Panels". Journal of Econometrics, 115, 53-74.

Jensen, M., \& Meckling, W., 1976. "Theory of The Firm: Managerial Behavior, Agency Costs, and Capital Structure". Journal of Financial Economics, 3(4), 305-360.

Levine, A., Lin, C.F., Chu, C.S.J, 2002. "Unit Root Test in Panel Data: Asymptotic and Finite Sample Properties, J. Econ, 108, $1-24$.

Menon, Udayakumari Vidhyasagara, 2016. "Impact of Capital Structure on Prices: Evidence from Oman". International
Journal of Economics and Finance, 8 (9), 249-257.

Munisi, Gibson, Niels Hermes and Trond Randoy, 2014. "Corporate Boards and Ownership Structure: Evidence From Sub-Saharan Africa". International Business Review, 23, 785-796.

Pedroni, P., 1995. "Panel Cointegration, Asymptotic and Finite Sample Properties of Pooled Time Series Tests with an Application to the PPP Hypothesis". Working Paper in Economics. Indiana University, 92-103.

Asymptotic and Finite Sample Properties of Pooled Time Series Tests with an Application to the PPP Hypothesis: New Results". Working Paper in Economics, Indiana University.

---------------, 1999. “Critical Values for Cointegration Tests in Heterogeneous Panels with Multiple Regressors". Oxf. Bull, Econ, Statistics, 61, 653-670.

--------------, 2000. "Fully Modified OLS for Heterogeneous Cointegrated Panels". Advances in Econometrics, 15, 93-130. Asymptotic and Finite Sample Properties of Pooled Time Series Tests with an Application to the PPP Hypothesis." Econ Theory, 20, 597-625.

Pirzada, Kashan., Mohd Zulkhairi bin Mustapha, Dantur Wickramasinghe, 2015. "Firm Performance, Institutional Ownership and Capital Structure: A Case of Malaysia". Procedia Social and Behavioral Sciences, 211, 170-176. 
Quang, Do Xuan and Wu Zhong Xin, 2013. "Impact of Ownership Structure and Corporate Governance on Capital Structure: The Case of Vietnamese Firms". Australian Journal of Business and Management Research, 3 (3), 11-19.

Sepasi, Sahar., Morteza Kazempour, and Roya Mansourlakoraj, 2016. "Ownership Structure and Disclosure Quality: Case of Iran". Procedia Economics and Finance, 36, 108-112.

Sun, Ji., Li Ding, Jie Michael Guo, and Yichen Li, 2016. "Ownership, Capital Structure and Financing Decision: Evidence from the UK." The British Accounting Review, $48,448-463$.
Vatavu, Sorana, 2015. "The Impact of Capital Structure on Financial Performance in Romanian Listed Companies". Procedia Economics and Finance, 31, 1314-1322.

Yu, Mei, 2013. "State Ownership and Firm Performance: Empirical Evidence from Chinese Listed Companies". China Journal of Accounting Research, 6, 7587. 